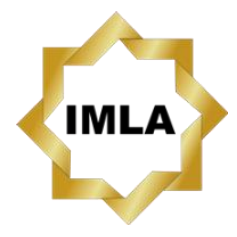

Available online:

http://journal.imla.or.id/index.php/arabi

Arabi : Journal of Arabic Studies, 4 (1), 2019, 75-86

DOI: http://dx.doi.org/10.24865/ajas.v4i1.124

\title{
EPISTIMOLOGI KURIKULUM BAHASA ARAB DI SEKOLAH MENENGAH MUTAWASITAH PIRAYA NAWIN KLONGHIN WITTAYA PATANI THAILAND SELATAN
}

\author{
Ahmad Nurcholis, Basmah Salaeh \\ Institut Agama Islam Negeri Tulungagung, Indonesia \\ E-mail : cholisahmad87@gmail.com
}

\begin{abstract}
This article aimed to discuss the discourse of learning Arabic, the nature and its benefits that has been obtained from a real phenomenological qualitative research at Piraya Nawin School in Wittaya Thailand. The epistemology of Arabic language curriculum development in Thailand focus on the use of Arabic as a media for both oral and written communication. This curriculum development aims to understand Qur'an, Hadith, and many other religion books written in Arabic. The curriculum development in this school was appropriate with the vision and mission, to build the the good character through Arabic habituation in the school environment. The operational standard for implementing the Arabic curriculum development was determined by the school itself, without any government intervention. For example, memorizing Arabic mufradat. There were some obstacles such as the students who were not interested in memorizing mufradat and less of discipline to go to school. Arabic still does not become an important thing for students as well as its probelmatics that pay little attention to the different aspects of student competence.
\end{abstract}

Keywords: epistemology, Arabic curriculum development, Thailand

\begin{abstract}
Abstrak
Artikel ini bertujuan mengupas diskursus pembelajaran bahasa Arab, hakikat dan manfaat mempelajarinya yang didapat dari data riil penelitian kualitatif fenomenologis di Sekolah Piraya Nawin klonghin Wittaya Thailand. Epistemologi pengembangan kurikulum bahasa Arab di Thailand bertumpu pada penggunaan bahasa Arab sebagai materi belajar media komunikasi komunikasi lisan maupun tulisan. Pengembangan kurikulum bahasa Arab bertujuan untuk memahami Al-qur an, Hadis, dan buku-buku Agama yang menggunakan bahasa Arab. Pengembangan kurikulum bahasa Arab di Sekolah Piraya Nawin Klonghin Wittaya disesuaikan dengan visi dan misi pembentukkan karakter peserta didik yang berakhlak mulia melalui pembiasaan bahasa Arab di lingkungan sekolah. Standar operasional pelaksanaan pengembangan kurikulum bahasa Arab juga ditentukan sendiri oleh sekolah, tanpa adanya campur tangan pihak pemerintah Thailand, misalnya program hafalan mufradàt bahasa Arab. Sedangkan faktor penghambat program ini di antaranya siswa kurang minat dalam menghafal mufradāt dan kurang disiplin dalam berangkat sekolah. Bahasa Arab masih dianggap belum penting bagi siswa sebagaimana problematika proses pembelajaran bahasa Arab yang kurang memperhatikan aspek perbedaan kompetensi peserta didik.
\end{abstract}

Kata Kunci: Epistemologi, Pengembangan kurikulum bahasa Arab, Thailand 


\section{Arabi : Journal of Arabic Studies}

\section{Pendahuluan}

Kurikulum merupakan salah satu alat untuk mencapai tujuan pendidikan, sekaligus merupakan pedoman dalam pelaksanaan pembelajaran pada semua jenis dan jenjang pendidikan. Tanpa kurikulum yang sesuai dan tepat akan sulit untuk mencapai tujuan dan sasaran pendidikan yang diinginkan. Sebagai alat yang penting untuk mencapai tujuan, kurikulum hendaknya adaptif terhadap perubahan zaman dan kemajuan ilmu pengetahuan serta canggihnya teknologi. Epistemologi kurikulum berkembang sejalan dengan perkembangan teori dan praktik pendidikan. Di samping itu, kurikulum harus bisa memberikan arahan dan patokan keahlian kepada peserta didik setelah menyelesaikan suatu program pengajaran pada suatu lembaga (Suparno, 2019). Oleh karena itu, wajar bila kurikulum selalu berubah dan berkembang sesuai dengan kemajuan zaman, ilmu pengetahuan dan teknologi yang sedang terjadi.

Penelitian yang dilakukan oleh Humaidi dalam jurnal Pendidikan Islam UIN Syarif Hidayatullah Jakarta menunjukkan bahwa epistemologi kurikulum selain sebagai cara, rencana, aturan-aturan, bahan pelajaran, dan pedoman dalam proses pembelajaran, ia juga bermakna sebagai peta realitas. Kurikulum diibaratkan seperti peta jalan dan peta dunia yang menjadi petunjuk dan arah bagi orang yang sedang melakukan perjalanan. Kurikulum menjadi peta realitas karena ia menjadi petunjuk, seperti hanya realitas dan wujud apa saja yang dapat dikaji dan dipelajari oleh manusia. Sebagi peta, ia berfungsi sebagai penunjuk arah untuk melihat, membaca, dan mengkaji wujud-wujud . Di samping itu, kurikulum dapat berfungsi dan digunakan sebagai alat oleh manusia untuk mengaktualkan potensi-potensinya, sehingga mereka dapat menjadi profesional dalam pendidikan (Humaidi, 2018).

Pada setiap lembaga pendidikan pasti memiliki visi dan misi tersendiri sesuai dengan tujuan lembaga yang didirikan. Masing-masing lembaga memiliki karateristik khas yang berbeda dengan lembaga lain. Bahkan, hal tersebut merupakan suatu keunggulan yang diistimewakan sebagai daya tarik masyarakat. Begitu pula lembaga sekolah Piraya Nawin Klonghin Wittaya. Lembaga ini memiliki epistimologi atau karakteristik tersendiri yang membedakannya dengan lembaga pendidikan lain. Khususnya di bidang pengembangan kurikulum bahasa Arab. Dengan demikian pembahasan ini adalah tentang bagaimana sekolah Piraya Nawin Klonghin Wittaya tetap mempertahankan corak pada kurikulumnya, namun juga tetap mampu mengaktualisasi eksistensinya di dalam masyarakat.

Berdasarkan latar belakang di atas, maka dapat dirumuskan permasalahan sebagai berikut: Bagaimana epistemologi pengembangan kurikulum bahasa Arab yang digunakan di sekolah Piraya Nawin Klonghin Wittaya Pattani (Selatan Thailand) dan meliputi apa saja? Sedangkan batasan masalah dalam penelitian ini, meliputi:

1. Batasan waktu. Dalam penelitian membatasi waktu penelitian pada tahun ajaran 2018/2019.

2. Batasan tempat. Batasan tempat dalam penelitian ini adalah sekolah menengah mutawasitah Piraya Nawin Klonghin Wittaya Pattani (Selatan Thailand).

3. Batasan kurikulum. Batasan kurikulum yang dikaji bedasarkan Undang-Undang Dasar kerajaan Thai (Kod Mai Raj Thammanun) tahun 1997 pasal 3 ayat 43 disebutkan bahwa setiap warga Thai memiliki hak yang sama untuk mendapatkan pendidikan formal dari tingkat dasar sampai menengah, yaitu 12 tahun. Dalam hal ini, pemerintah harus menyelenggarakannya tanpa memungut biaya apapun" (UUD Kerajaan Thai, 2019). Dalam merealisasi undang-undang tersebut, sistem pendidikan formal baik dari tingkat dasar maupun menengah diselenggarakan oleh pemerintah dan swasta. Sistem pendidikan formal yang diselenggarakan tersebut tidak lepas dari tujuan nasional yang merupakan tujuan umumnya. Maka kurikulum yang diterapkan adalah kurikulum nasional.

4. Batasan Bidang. Penelitian membatasi bidang kegiatan pembelajaran bahasa Arab. 


\section{Pengembangan Epistemologi Kurikulum Bahasa Arab}

Yang dimaksud dengan pengembangan epistemologi bahasa Arab adalah pengokohan bangunan keilmuan bahasa Arab agar arah pengembangan pengkajian bahasa Arab lebih dinamis. Dari bangunan epistemologi inilah, struktur keilmuan dapat dikembangkan lebih jauh dalam kurikulum bahasa Arab. Berikut ini adalah beberapa pokok pikiran mengenai model pengembangan epistemologi dan kurikulum bahasa Arab.

a. Revitalisasi sinergi ilmu bahasa Arab dan ilmu-ilmu lain yang mempunyai kedekatan bidang kajian, sehingga terjadi proses" take and give (al-akhdz wa al-'athā), seperti: 'ilm Nashsh (tekstologi) (Van Dijk, 2018), 'ilm al-makhathüthät (filologi) (Abu Zaid, 2017), 'ilm al-uslūb (stilistika), dan sebagainya.

b. Pengembangan cabang-cabang bahasa Arab menjadi ilmu mandiri, seperti:' 'ilm altarjamah, 'ilm al-insyā, 'ilm ushūl al-nahwi, ilm al-mu'jam (leksikografi), dan sebagainya, sehingga ilmu-ilmu ini tidak hanya sekedar" suplemen, tetapi menjadi ilmu yang lebih substantif, sistematis, dan mendalam. Seiring dengan semakin menguatnya basis dan tradisi keilmuan, jika memungkinkan di suatu saat nanti, akan muncul kampus-kampus yang dapat membuka program studi atau peminatan: metodologi penelitian bahasa Arab, tarjamaah Arab-Indonesia, metodologi pembelajaran bahasa Arab, pengembangan kurikulum bahasa Arab, teknologi pendidikan bahasa Arab, dan sebagainya.

c. Pembandingan, adaptasi, dan improvisasi ilmu bahasa Arab dengan bahasa Inggris dan Perancis yang saat ini lebih maju dan modern. Upaya ini sebetulnya sudah dilakukan, terutama dalam konteks pembagian metodologi pembelajaran bahasa Arab. Di antaranya adalah Kamal Ibrahim Badri, Muhammad Ismail Shini, Rusydi Ahmad Thu'aimah, Mahmud Kamil al-Naqah, Rusydi Khathir, dan Abduh al-Rajihi. Semua tokoh tersebut pernah mengenyam pendidikan tinggi di Barat, seperti Amerika, Perancis, Inggris, dan Jerman.

d. Revitalisasi pendasaran dan pengaitan pengembangan penelitian bahasa Arab dengan nuansa Islam dan sumber utama ajaran Islam, yaitu: Alquran dan Hadis. Dewasa ini cukup marak dilakukan oleh para sarjana di perguruan tinggi Arab. Beberapa karya yang dapat disebut di sini, antara lain: al-Isytirāk, al-Lafzhì fi al-Qurān al-Karīm Baina al-Nazhariyyah wa alTathbiqq, karya Muhammad Nuruddin al-Munajjid (1999), al-Nahw al-Qurani: Qawā'id wa Syawāhid karya Jamîl Ahmad Dhafr (1998), dan al-Manhaj al-Islāmī fi al-Naqd al-Adabī karya Sayyid Sayyid Abd al-Razzaq (2001).

e. Penguatan penelitian dan pendidikan bahasa Arab melalui aplikasi dan improvisasi linguistik modern dan pengalaman positif di bidang pembelajaran bahasa dari Barat dengan tetap mempertahankan kekhususan atau karakteristik ilmu-ilmu bahasa Arab, baik fonologi, morfologi, sintaksis, maupun semantiknya. Upaya semacam ini, antara lain, terlihat dalam beberapa karya seperti: Dirāsat Nahwiyyah wa Dilāliyah wa Falsafiyyah fi Dhaui alLisāniyyah al-Mu'āshirah karya Mâzin Al-War (2001), dan lain-lain.

\section{Pengembangan Kurikulum}

a. Komponen Kurikulum (Sulung, 2016)

Salah satu fungsi kurikulum ialah sebagai akar untuk mencari tujuan pendidikan. Kurikulum pada dasarnya memiliki komponenkomponen penunjang yang saling berkaitan dan berintegrasi satu sama lainnya dalam rangka pencapai tujuan tersebut. Menurut Subandijah terdapat lima komponen kurikulum (Subandijah, 2015).

1) Komponen tujuan

Tujuan merupakan hal yang paling penting dicapai oleh sekolah secara keseluruhan yang mencakup tiga dimensi yaitu dimensi kognitif, psikomotorik, dan afektif. Secara hirarkis tujuan pendidikan tersebut dari yang paling tinggi sampai yang paling rendah dapat diurutkan sebagai berikut: 


\section{Arabi : Journal of Arabic Studies}

a) Tingkat pendidikan nasional

b) Tingkat institusional dan tujuan kelembagaan

c) Tingkat kurikuler (tujuan mata pelajaran atau bidang studi)

d) Tujuan instruksional (tujuan pembelajaran)

Menurut UU Pendidikan Nasional tahun 2542 (1999) Pasal 6 dalam mengelola pendidikan harus dapat mengembangkan warga Thailand yang sempuran jasmani, rohani, kecerdasan, ilmu pengetahuan, serta moral, kebudayaan, dan adat dalam kehidupan sehari-hari sehingga mampu hidup berdampingan dengan orang lain. Pasal 7 dalam proses pembelajaran harus dapat menanam kesadaran yang benar tentang politik dan pemerintahan dalam sistem demokrasi di mana Raja sebagai Kepala Negara. Membela hak asasi manusia, mengikuti undang-undang dasar, saling menghormati satu dengan yang lain, merasa bangga sebagai warga Thailand, menjaga kepentingan umum dan negara termasuk mengembangkan kebudayaan produk lokal dan ilmu pengetahuan universal, dan melestarikan sumber alam dan lingkungan menjadi karier yang kreatif, profesional dan memiliki rasa ingin tahu dalam mencari ilmu pengetahuan (UUD Kerajaan Thai, 2019).

2) Komponen Isi Kurikulum

Faududdin mengemukan beberapa kriteria yang digunakan untuk menyusun materi kurikulum, sebagai berikut:

a) Continuitas (kesinambungan)

b) Sequeance (urutan)

c) Integration (keterpaduan)

d) Flexibility (keluesan atau kelenturan)

Yang diprogramkan untuk mencapai tujuan pendidikan yang telah ditetapkan. Isi atau materi tersebut biasanya berupa materi mata pelajaran, seperti Pendidikan bahasa Arab, yang meliputi Alquran, hadis, fikih, sejarah Islam, bahasa Arab, dan sebagainya (Faududdin, 2018).

3) Komponen media atau sarana prasarana

Media merupakan perantara untuk menjelaskan isi kurikulum agar lebih mudah dipahami oleh peserta didik baik. Guru dapat menggunakan satu media atau lebih yang diharapkan dalam rangka mempermudah proses pembelajaran.

4) Komponen strategi

Pada hakikatnya strategi pengajaran tidak hanya terbatas pada hal itu saja, tetapi menyangkut berbagai macam yang diusahakan oleh guru dalam mengajar siswanya dangan kata lain mengatur seluruh komponen baik pokok maupun penunjang dalam sistem pengajaran.

5) Komponen belajar mengajar

Komponen ini sangat penting dalam sistem pengajaran, sebab keberhasilan proses belajar mengajar merupakan suatu indikator keberhasilan pelaksanaan kurikulum. Oleh karena itu, proses belajar mengajar harus dapat menciptakan suasana yang kondusif sehingga memungkinkan dan mendorong peserta didik untuk secara dewasa mengembangkan kreativitas melalui bantuan guru.

\section{b. Kurikulum Pendidikan Bahasa Arab}

Kurikulum Thailand meliputi sejumlah pengalaman pendidikan bahasa Alquran, kebudayaan, sosial, olahraga, dan kesenian yang disediakan oleh sekolah bagi siswa-siswa di dalam dan di luar sekolah dalam rangka meningkat perkembangan siswa secara menyeluruh dalam semua bidang dan merubah tingkah laku mereka sesuai dengan tujuan-tujuan pendidikan (Hasan dan Beni, 2017).

Dari definisi tersebut di atas dapat disimpulkan bahwa kurikulum mempunyai empat unsur utama, yaitu:

1) Tujuan-tujuan yang ingin dicapai oleh pendidikan itu.

2) Pengetahuan, informasi-informasi, data-data, aktivitas-aktivitas, dan pengalamanpengalaman dari mana bentuk kurikulum itu.

3) Metode dan cara mengajar yang dipakai oleh guru-guru untuk mengajar dan mendorong minat belajar siswa dan membawa mereka ke arah yang dikehendaki oleh kurikulum.

4) Metode dan cara penilaian yang digunakan. 


\section{Perkembangan Pendidikan Bahasa Arab di Pattani Thailand \\ a. Pendidikan di Masjid dan Surau}

Masjid dan surau di Patani bukan hanya berfungsi sebagai tempat ibadah, tetapi juga berfungsi sebagai lembaga pendidikan Islam. Masjid dan surau sejak dari dulu telah memegang peranan penting dalam penyebaran agama Islam di Patani, Melalui lembaga tersebut para ulama dapat menyampaikan ajaran Islam kepada masyarakat dalam bentuk pengajian agama secara rutin. Adapun pengajian diterapkan di masjid ini di antaranya adalah belajar membaca Alquran, belajar kitab-kitab Jawi (kuning), belajar membaca mauled barzanji, dan belajar menjadi imam sholat.

\section{b. Pendidikan Pondok Tradisional}

Pondok berposisi sebagai lembaga pendidikan yang sangat penting di Thailand Selatan. Perkembangan pendidikan Islam di Patani terlaksana melalui sistem pondok. Pondok berasal dari bahasa Arab "Funduq" artinya bangunan untuk pengembara. Guru yang mengajar di sana disebut sebagai Tuan Guru atau Tok guru, dan diakui keahliannya oleh penduduk kampung untuk mengajar mereka yang ingin melanjutkan pengajian agama Islam (Malik, 2016). Pelajar-pelajar yang tinggal di pondok disebut" Tuk Pake" (santri). Pondok adalah lembaga pendidikan tertua di Patani dan di antara pondok-pondok tertua itu adalah pondok Dala, Bermin, Semela, Dual, Kota, Gersih, Telok Manok, yang mempunyai pengaruh besar bagi pertumbuhan pendidikan Islam di daerah ini oleh karena pondok-pondok ini banyak didatangi pelajar-pelajar dari luar Patani. Oleh karena itu, pondok-pondok ini sangat mempengaruhi perkembangan bahasa Melayu. Bahkan pengaruhnya juga sampai ke Brunei dan Kamboja. Di antara pondok yang yang cukup lama dan terkenal di Thailand Selatan, yaitu Pondok Tok Guru Haji Nor, Pondok Tok Guru Haji Leh, dan Pondok Guru Haji Somad (al-Fathoni, 2019).

\section{c. Pendidikan Madrasah}

Pada tahun 1933 Haji Sulong mendirikan sekolah modern pertama di Patani sebagaimana ditulis oleh Chalermkiat Khuntongpech bahwa proyek pembangunan sekolah Agama pertama di Patani mulai dibangun pada akhir tahun 1933 dengan jumlah dana 7200 Bath. Disumbangkan oleh umat Muslim yang berada di kampung anak $\mathrm{Ru}$ dan sekitarnya dengan diberi nama Madrasah AlMaarif Al-Wathaniyah Fathoni, kemudian sekolah ini diselesaikan dan dibuka secara resmi oleh Perdana Menteri Thai (Mahmud, 2015). Madrasah ini merupakan sekolah agama pertama yang didirikan di tanah Patani. Madrasah ini adalah sebuah madrasah model baru yang bukan hanya memiliki tingkatan mata pelajaran dan bersistem kelas tetapi juga menjadi istimewa karena adanya latihan baris berbaris. Pendidikan madrasah ini hanya mampu aktif selama tiga tahun. Namun hal ini tentunya menjadi pedoman bagi pertumbuhan madrasah yang lain setelahnya. Adapun tingkat pendidikan di lembaga madrasah dimulai dari tingkat ibtidaiyah, kemudian berkembang menjadi Mutawasitah, dan tingkat Tsanawiyah. Sistem pengajian agama di madrasah mengutamakan sistem talaqqi dan sistem turats.

\section{d. Pendidikan Pondok Modern (Sekolah Swasta Pendidikan Bahasa Arab)}

Lembaga ini merupakan lembaga pendidikan hasil tranformasi dari lembaga pondok pesantren tradisional ke pondok pesantren modern. Semua kegiatan diatur oleh pemerintah Thailand. Sistem pendidikan ini dilaksanakan dalam bentuk dualisme semi-sekuler, yaitu: Pertama: Pendidikan agama tingkat Ibtidaiyah, Mutawasitah, dan Tsanawiyah. Kedua: Pendidikan umum dari tingkat menengah pertama (SLTP) dan menengah atas (SLTA). Adapun kurikulum yang dipakai dalam penyelenggarakanpendidikan di pondok terbagi 2 bagian, yaitu:

1) Bagian Agama

a) Kurikulum pendidikan Islam tingkat Dasar atau tingkat Ibtidaiyah, selama 4 tahun sama dengan 8 semester.

b) Kurikulum pendidikan Islam tingkat Menengah atau tingkat Muatawasitah, selama 3 tahun sama dengan 6 semester. 


\section{Arabi : Journal of Arabic Studies}

c) Kurikulum pendidikan Islam tingkat Atas atau Tsanawiyah, selama 3 tahun sama dengan 6 semester.

2) Bagian Umum

a) Kurikulum pendidikan umum tingkat pertama, selama 3 tahun sama dengan 6 semester.

b) Kurikulum pendidikan umum tingkat atas, selama 3 tahun sama dengan 6 semester (Fauziah, 2016).

\section{Metode Penelitian}

Penelitian ini menggunakan pendekatan kualitatif. Yang dimaksud pendekatan kualitatif adalah penelitian yang menghasilkan penemuan-penemuan yang tidak dapat dicapai dengan menggunakan prosedur statistik atau dengan cara-cara kuantitatif (Ghony \& Almanshur, 2017).

Dalam kehadiran peneliti secara langsung di lapangan sebagai tolak ukur keberhasilan untuk memahami sesuatu yang diteliti, sehingga keterlibatan peneliti secara langsung dan aktif dengan informasi dan sumber data lainnya di sini mutlak diperlukan. Kehadiran peneliti merupakan hal yang sangat penting dalam mengamati dan mendapatkan data yang valid, karena penelitian ini menggunakan pendekatan kualitatif yang menekankan pada latar belakang yang alami dari objek penelitian yang dikaji, yaitu kurikulum pendidikan bahasa Arab di Sekolah Menengah Piraya Nawin Klonghin Wittaya, peranan guru dalam mengaplikasikan kurikulum pendidikan bahasa Arab dan melaksanakan evaluasi kurikulum pendidikan bahasa Arab di sekolah tersebut.

Penelitian dilaksanakan di Sekolah Menengah Piraya Nawin Klonghin Wittaya, Patani (Thailand Selatan) dengan alasan terdapat sesuatu yang unik, yaitu kegiatan religius yang langka dan tidak ditemukan di sekolah umum lainnya, serta peranan guru pendidikan bahasa Arab dalam mengaplikasikan kurikulum pendidikan bahasa Arab. Selain itu:

a. Adanya unik kegiatan Tahfizul Qurān bagi siswa Mutawasitah dalam tempo waktu yang ditetapkan.

b. Adanya motivasi dari guru pendidikan bahasa Arab kepada siswa-siswinya agar tertib dalam mengikuti kegiatan keagamaan yang dilakukan oleh sekolah.

c. Semangat peserta didik yang sangat tinggi untuk ikut berpartisipasi dalam kegiatan keagamaan.

d. Serta fasilitas dan sumber belajar yang digunakan dalam kegiatan keagamaan sudah memadai.

Sumber data di dalam penelitian ini dibagi menjadi dua, yaitu data primer dan data sekunder. Data primer diperoleh melalui hasil wawancara dengan narasumber, hasil observasi dari subyek yang diteliti, serta dokumentasi berupa data-data penting yang menjadi penunjang dalam memperkuat hasil penelitian. Data sekunder diperoleh melalui dokumen profil sekolah yang diteliti, jumlah guru seluruhnya, jumlah peserta didik, foto, serta dokumen pendukung lainnya.

Penelitian ini menggunakan beberapa teknik pengumpulan data, yaitu:

a. Wawancara tidak terstruktur

b. Observasi non-partisipan

c. Studi Dokumentasi

Dokumen yang digunakan dalam penelitian ini meliputi: foto, tabel, arsip wawancara, serta arsip observasi dan digunakan untuk memperoleh data mengenai kurikulum pendidikan bahasa Arab dan peranan guru dalam mengaplikasikan kurikulum pendidikan bahasa Arab dan serta evaluasi kurikulum pendidikan bahasa Arab di sekolah menengah Piraya Nawin Klonghin Wittaya.

Analisis data dalam penelitian kualitatif ini dilakukan pada saat pengumpulan data berlangsung dan setelah selesai pengumpulan data dalam periode tertentu. Ada tiga teknik dalam menganalisis data, yaitu:

a. Data Reduction (Reduksi Data)

b. Data Display (Penyajian Data)

c. Conclusion Drawing (Penarikan Kesimpulan) 
Pengecekan keabsahan data dalam penelitian tidak hanya menggunakan satu teknik, tetapi dengan menggunakan beberapa teknik, antara lain:

a. Pemeriksaan sejawat melalui diskusi

b. Triangulasi

c. Keajegan pengamatan

\section{Hasil Penelitian}

\section{Pelaksanaan Kurikulum Pendidikan Bahasa Arab di Sekolah Piraya Nawin Klonghin Wittaya}

Hasil penelitian tentang pelaksanaan kurikulum pendidikan bahasa Arab di Sekolah Piraya Nawin Klonghin Wittaya dapat dilihat dari kutipan wawancara seperti yang akan dijelaskan dibawah ini:“ Hasil dari pelaksanaan kurikulum pada umumnya menunjukkan bahwa siswa yang ada di sekolah Piraya Nawin ini masih banyak kekurangan yang harus diperbaki karena para siswa bukanlah orang yang bisa melaksanakan kurikulum yang digunakan di sekolah secara keseluruhan, tetapi beberapa siswa juga sangat berhasil dengan melaksanakan tugas kurikulum yang digunakan di sekolah ini (Hajidoloh, 2019).

Jenis kurikulum di sekolah ini relatif sama dengan kurikulum yang ada di sekolah umum. Yang membedakan hanya sekolah ini menambahkan kurikulum Mini English Program (MEP), Quran \& Sciece Program (QSP), Math Program (MP), Quran Science English Program (Q-SEP), Quran \& Mini English Program (Q-MEP) dan Science \& Math Program (SMP) (Piraya Guide Book, 2016). Materi yang diajarkan juga ditentukan secara mandiri oleh sekolah ini sesuai dengan kurikulum yang tercantum dalam kurikulum standar nasional oleh menteri pendidikan. Materi yang diberikan adalah materi yang berkaitan dengan Keagamaan, Kesehatan, Sosial, dan Budaya.

Di sekolah ini terdapat beberapa kegiatan-kegiatan keagamaan yang biasa dilakukan sebagai penunjang kegiatan pembelajaran, seperti yang tertera dalam wawancara berikut ini: Untuk kegiatan keagamaan, semua warga sekolah melaksanakan shalat lima waktu secara berjamaah kemudian melaksanakan buka puasa bersama bulan Ramadan di masjid-masjid lingkungan sekitar sekolah lalu dilanjutkan dengan shalat tarawih berjamaah. Petugas imam tarawih berasal dari siswa sekolah (Waekaji, 2019).

a. Waktu dan Jadwal Pembelajaran

Pembelajaran secara keseluruhan di Sekolah Piraya Nawin dimulai pukul 08.00. Sebelum masuk kelas dan memulai pelajaran, siswa berbaris di halaman dan menyanyikan lagu kebangsaan dan mars sekolah dan dilanjutkan berdoa bersama-sama yang dipimpin oleh seorang dewan siswa (presiden sekolah). setelah ini mereka masuk kelas untuk memulai pelajaran. Hal itu sudah menjadi rutinitas di sekolah ini. Selanjutnya untuk pembelajaran bahasa Arab jenjang Mutawasitah di sekolah ini sebagaimana dikatakan oleh wakil kepala sekolah, sebagai berikut: pembelajaran bahasa Arab dilaksanakan selama 6 jam pelajaran dalam seminggu, dengan alokasi waktu pembelajaran hanya 40 menit/jam, dan waktu pelaksanaannya pada pagi hari mulai 08.00-12.00 waktu setempat dan dilanjutkan lagi pada pukul 13.00-15.00 waktu setempat. Tetapi hal itu bercampur dengan mata pelajaran akademik lainnya, bukan hanya mata pelajaran agama sesuai dengan kurikulum integrasi (Hajidoloh, 2019).

b. Materi Pembelajaran

Materi adalah bahan-bahan yang harus diberikan atau disajikan kepada peserta didik untuk mencapai tujuan pendidikan. Materi yang diajarkan di sekolah Piraya Nawin Klonghin Wittaya ditentukan secara mandiri oleh pihak sekolah sesuai dengan kurikulum sekolah. Materi yang diberikan adalah materi yang berkaitan dengan keseharian suasana pembiasaan kehidupan Islami dengan pendekatan tematik. Materi pelajaran yang telah diprogramkan dalam kurikulum pembelajaran bahasa Arab di sekolah ini dikelompokkan menjadi materi sebagai berikut:

1) Materi Alquran

Materi Alquran di sekolah Piraya Nawin Klonghin Wittaya yang telah diprogramkan dalam kurikulum pendidikan bahasa Arab diberikan dalam bentuk penyajian materi dalam bentuk 


\section{Arabi : Journal of Arabic Studies}

membaca serta menghafal surat-surat pendek dengan baik dan lancar (Kurikulum sekolah Piraya Nawin Klonghin Wittaya, 2019).

2) Materi Akhlak

Materi Akhlak yang diajarkan di Sekolah Piraya Nawin Klonghin Wittaya, meliputi budi pekerti yang baik, sifat terpuji, sifat tercela, adab sopan santun, adab pergaulan dengan orang tua dan sesama dalam rangka memberikan bimbingan dan tauladan tentang bagaimana berakhlak yang baik (Kurikulum sekolah Piraya Nawin Klonghin Wittaya, 2019).

3) Materi Tauhid (Keimanan)

Tujuan memberikan materi Tauhid di sekolah ini supaya tertanam perasaan keimanan dan ketaqwaan yang kuat kepada Allah SWT di dalam jiwa dan sanubari peserta didik serta cinta dan patuh kepada Allah SWT.

4) Materi Fikih

Materi Fikih yang diberikan di sekolah Piraya Nawin Klonghin Wittaya meliputi pembahasan masalah syari'ah dan ibadah karena materi tersebut merupakan jalan yang harus dilalui oleh setiap umat Islam untuk menjalankan hukum Islam.

5) Materi Hadits

Materi Hadis diberikan di Sekolah Piraya Nawin Klonghin Wittaya dengan tujuan agar peserta didik dapat mencontohkan perilaku dan akhlak Rasulullah SAW dalam kehidupan seharihari.

6) Bahasa Melayu jawi

Materi bahasa Melayu Jawi diberikan di Sekolah Piraya Nawin Klonghin Wittaya karena merupakan bahasa nenek moyang semenjak zaman dahulu sehingga siswa dapat berkomunikasi dalam aktivitas sehari-hari dengan menggunakan bahasa melayu dan juga agar bahasa Melayu Jawi tidak hilang dari Provinsi Pattani.

7) Tafsir

Materi Tafsir diberikan di Sekolah Piraya Nawin Klonghin Wittaya dengan tujuan agar peserta didik dapat mengetahui tafsir ayat-ayat Alquran beserta ilmu-ilmu lainnya.

8) Bahasa Arab

Materi bahasa Arab di Sekolah Piraya Nawin Klonghin Wittaya yang telah diprogramkan diadakan pada tingkat Mutawassitah dan tingkat Tsanawiyah disajikan dalam bentuk membaca teks-teks serta menghafal mufradat bahasa Arab dengan terjemah bahasa Melayu. Materi dan kitab pembelajaran bahasa Arab telah ditentukan secara mandiri oleh sekolah.

Materi pembelajaran bahasa Arab disesuaikan dengan kondisi peserta didik. Dalam proses pembelajaran bahasa Arab, guru lebih menekankan pada materi Alquran dan Akhlak karena dengan menekankan materi Alquran dan Akhlak diharapkan siswa dapat berakhlak dan bertingkah laku dengan baik kepada orang tua, guru, dan teman, baik di lingkungan keluarga, sekolah, maupun masyarakat luas, serta juga dapat melaksanakan shalat secara konsisten dalam kehidupan seharihari.

\section{c. Metode Pembelajaran}

Metode pembelajaran adalah suatu pengetahuan tantang cara-cara mengajar yang dipergunakan oleh seorang guru. Dengan kata lain merupakan teknik penyajian yang dikuasai guru untuk mengajar atau menyajikan bahan pelajaran kepada siswa di dalam kelas, baik secara individual maupun secara kelompok, agar materi pelajaran itu dapat diserap, dipahami, dan dimanfaatkan oleh siswa dengan baik. Makin baik cara mengajarnya, makin efektif pula pencapaian tujuannya. Hasil pengamatan dan wawancara dengan guru tentang proses belajar mengajar menunjukkan bahwa $80 \%$ guru menggunakan metode-metode, seperti metode tanya jawab, metode metode hafalan, metode diskusi, metode pemberian tugas belajar, metode kisah, dan metode latihan. 


\section{d. Evaluasi Kurikulum Pembelajaran}

Evaluasi merupakan alat untuk mengukur sampai di mana kemampuan anak didik menguasai materi yang telah diberikan. Evaluasi dapat dijadikan oleh sekolah sebagai bahan instropeksi diri, dengan melihat sejauh mana kondisi belajar yang diciptakannya. Evaluasi pembelajaran yang dilaksanakan di Sekolah Piraya Nawin Klonghin Wittaya menggunakan tes dan non-tes. Tes dilakukan pada waktu UTS dan UAS. Soal ujian disusun dengan disesuaikan dengan keadaan siswa. Hasil wawancara menunjukkan bahwa bentuk soal terdiri dari dua bentuk, yaitu menjawab soal dan melengkapi kalimat. Evaluasi non-tes dinilai dari perkembangan dan keaktifan siswa saat mengikuti pelajaran. Masalah yang muncul terkadang ada siswa di dalam kelas yang lebih banyak melamun dan tidak bisa menangkap pelajaran (Hajidoloh, 2019).

Dari kutipan wawancara di atas, nampak ada dua bentuk penilaian yang dilakukan di Sekolah Piraya Nawin, yaitu jenis penilaian tes dan non-tes. Sedangkan untuk penilaian tes, menggunakan soal tes tertulis, yaitu:

a) Menjawab soal

b) Melengkapi kalimat

Hasil pembelajaran merupakan barometer bagi baik atau buruknya pembelajaran yang telah dilakukan. Hal tersebut dapat mengukur sejauh mana pembelajaran sudah berjalan sesuai dengan tujuan pembelajaran yang telah ditetapkan atau belum. Indikasi keberhasilan dari proses pembelajaran bahasa Arab di Sekolah Piraya Nawin Klonghin Wittaya, antara lain: kebiasaan buruk siswa sedikit demi sedikit sudah berkurang; siswa dapat menunjukkan perilaku yang baik dalam kehidupan sehari-hari, baik sesama guru, teman, dan orang tua; siswa dapat melakukan shalat dan wudhu sesuai dengan syari'at agama; serta siswa dapat menulis dan menghafal Alquran dan mufradat bahasa Arab. Pelajaran bahasa Arab disajikan dalam bentuk terbatas pada kalimat sederhana, hal ini dikarenakan keterbatasan intelektual mereka.

\section{Hasil Pelaksanaan Kurikulum Pendidikan Bahasa Arab di sekolah Piraya Nawin Klonghin Wittaya}

Hasil penelitian melalui wawancara mengenai hasil pelaksanaan kurikulum pendidikan bahasa Arab di sekolah Piraya Nawin Klonghin Wittaya menjelaskan bahwa tingkat keberhasilan pelajar belum bisa maksimal karena terkadang proses pembelajaran belum bisa maksimal mengimbangi kurikulum yang sudah modern. Meskipun demikian sudah ada perubahan yang signifikan, seperti siswa yang sebelumnya hanya melamun saja di kelas ketika awal sekolah, namun lama kelamaan mereka dapat merasa lebih nyaman dan mengimbangi proses pembelajaran di sekolah kami (Hajidoloh, 2019).

Dari kutipan wawancara tersebut, terlihat jelas bahwa pelaksanaan kurikulum pembelajaran bahasa Arab di Sekolah Piraya Nawin sudah dapat dikatakan berhasil meskipun belum optimal. Sekolah Piraya Nawin Klonghin Wittaya juga selalu mengupayakan adanya komunikasi antara lembaga sekolah dengan wali siswa mengenai perkembangan siswa mengenai hasil pembelajaran. Hal ini dapat dilihat dari hasil wawancara sebagai berikut: "Kita upayakan untuk selalu ada komunikasi antara pihak sekolah dengan wali siswa, untuk pertemuan rutin dengan wali siswa kita tidak ada agenda khusus, kondisional seperti ketika kita mau UAS/UTS, kita adakan pertemuan dengan wali siswa, untuk acaranya bertukar pendapat bersama untuk mengetahui tingkah laku anak ketika di rumah maupun di sekolah" (Hajidoloh, 2019). Wawancara dengan ustadz Zofron tersebut menegaskan bahwa sekolah Piraya Nawin Klonghin Wittaya juga selalu mengomunikasikan setiap permasalahan dengan seluruh unsur terkait dengan kebijakan-kebijakan lembaga.

\section{Faktor Pendukung dan Penghambat Pembelajaran di sekolah Piraya Nawin Klonghin Wittaya}

Dalam pelaksanaan kurikulum pendidikan bahasa Arab di sekolah Piraya Nawin tentunya tidak terlepas dari hal-hal yang mendukung dan menghambat. Hasil wawancara berikut 


\section{Arabi : Journal of Arabic Studies}

menggambarkan hal tersebut: "Untuk faktor pendukungnya, guru-guru di sini semuanya dituntut untuk selalu sabar dan tekun dalam menangani anak-anak didiknya, pembelajaran mereka itu seperti privat, disesuaikan dengan kebutuhan anak. Keberadaan Sekolah ini juga mendapat dukungan dari pemerintah dan lingkungan. Untuk faktor penghambat di antaranya kurang disiplinnya siswa dalam masuk sekolah, dan perhatian yang kurang dari wali siswa".

Seringkali guru sudah siap mengajar akan tetapi para siswa belum ada yang datang. Terkadang juga pembelajaran yang seharusnya mulai jam 08.00, akan tetapi mereka datang jam 08.10 atau bahkan lebih (Abubakar, 2019). Hal yang sama diungkapkan mengenai pendukung dan penghambat pembelajaran bahasa Arab, sebagai berikut: Untuk faktor pendukung, sekolah ini didukung oleh pemerintah dan linkungan, selain itu guru-guru mengajar juga dengan penuh rasa ikhlas dan sabar. Karena para guru menyadari bahwa mengajar di Sekolah Piraya Nawin merupakan suatu perjuangan. Faktor pendukung lainnya, guru-guru pendidikan bahasa Arab di sekolah ini berlatar belakang pendidikan secara keseluruhan di bidang agama Islam. Kemudian untuk faktor penghambat, siswa sulit sekali masuk sekolah, dan orang tua mereka juga kurang perhatian terhadap anak mereka dan sekolah ini masih kekurangan guru bahasa Arab (Hajidoloh, 2019). Dari beberapa kutipan wawancara tersebut di atas, dapat dimaklumi bahwa hal-hal yang mendukung pembelajaran bahasa Arab di sekolah Piraya Nawin, di antaranya guru yang selalu sabar, telaten, dan berlatar belakang pendidikan keagamaan Islam.

\section{Pembahasan}

Sekolah Piraya Nawin Klonghin Wittaya merupakan salah satu lembaga pendidikan menangani siswa-siswi yang mempunyai intelektual yang rendah. Melalui sekolah ini diharapkan mereka memiliki kemampuan intelektual meskipun tidak terlalu maksimal. Terlebih pada mata pelajaran pendidikan bahasa Arab yang implementasinya sangat berpengaruh dalam kehidupan beragama siswa.

Kurikulum yang digunakan sebagai acuan pembelajaran bahasa Arab di Sekolah Piraya Nawin Klonghin Wittaya adalah Kurikulum 46, sebagaimana yang telah ditetapkan oleh pemerintah. Kurikulum 46 memungkinkan guru untuk melakukan modifikasi, sehingga pembelajaran dapat disesuaikan dengan kebutuhan siswa dan aplikasi pembelajarannya hanya pada materi-materi tertentu. Hal penting yang harus diperhatikan dalam membedakan antara kurikulum pendidikan umum dan pendidikan khusus adalah ciri pembelajaran dan penilaian pada pendidikan khusus dengan memperhatikan karakteristik, kemampuan, keterbatasan, baik secara emosional, intelektual, fisik, maupun etika peserta didik. Kondisi ini membuat prinsip belajar pada pendidikan khusus menganut prinsip belajar yang fleksibel, baik dilihat dari segi waktu, materi, maupun penilaian.

Untuk menyusun isi kurikulum harus disesuaikan dengan tingkat dan jenjang pendidikan, perkembangan yang terjadi dalam masyarakat, perkembangan ilmu pengetahuan, dan juga tidak terlepas kaitannya dengan anak didik (psikologi anak) pada setiap jenjang pendidikan tersebut. Berdasarkan tuntutan kurikulum 46 untuk pendidikan bahasa Arab bagi jenjang mutawasitah, standar kompetensi yang harus di kuasai antara lain sebagai berikut:

1) Menerapkan tata cara membaca Alquran menurut tajwid

2) Menghafalkan mufradat bahasa Arab dan memahami teks-teks bahasa Arab

3) Meningkatkan pengenalan dan keyakinan terhadap aspek-aspek rukun Iman dan Islam

4) Menjelaskan dan membiasakan perilaku terpuji

5) Menjelaskan tata cara mandi wajib dan shalat wajib maupun shalat sunnah

6) Memahami dan meneladani sejarah Nabi Muhammad SAW dan para sahabat serta menceritakan sejarah masuk dan berkembangnya Islam di nusantara

Tuntutan kurikulum semacam ini dibebankan kepada para siswa mutawasitah pada umumnya, sementara bagi Sekolah Piraya Nawin Klonghin Wittaya diberikan kebijakan tersendiri untuk melaksanakan tuntutan tersebut. Ada kekhususan yang diberikan kepada sekolah ini, antara 
lain terletak pada penyesuaian dengan kebutuhan peserta didik. Materi yang diajarkan di Sekolah ini juga ditentukan sendiri oleh sekolah sesuai dengan kurikulum sekolah. Adapun materi yang diberikan adalah materi yang berkaitan dengan keseharian sesuai dengan suasana pembiasaan kehidupan Islami dengan pendekatan tematik.

\section{Simpulan}

Pengembangan epistemologi bahasa Arab adalah pengokohan bangunan keilmuan bahasa Arab agar arah pengembangan pengkajian bahasa Arab lebih dinamis. Dari bangunan epistemologi inilah, struktur keilmuan dapat dikembangkan lebih jauh dalam kurikulum bahasa Arab. Keberadaan Sekolah Piraya Nawin Klonghin Wittaya mendapat dukungan dari pemerintah dan lingkungan. Kurikulum bahasa Arab di Sekolah Piraya Nawin Klonghin Wittaya pada dasarnya relatif tidak berbeda jauh dengan kurikulum di sekolah umum, hanya saja yang membedakan Sekolah Piraya Nawin Klonghin Wittaya dengan yang lainnya adalah tersedianya kurikulum tambahan. Materi yang diajarkan ditentukan secara mandiri oleh sekolah dan materi yang diberikan adalah materi yang berkaitan dengan keseharian suasana pembiasaan kehidupan Islami dengan pendekatan tematik. Faktor pendukung dari pelaksanaan kurikulum bahasa Arab di antaranya para guru yang selalu sabar dalam mengajar, latar belakang pendidikan guru yang sudah sesuai, keberadaan sekolah Piraya Nawin yang didukung oleh pemerintah dan direktorat lingkungan sekitar, dan menambahkan pelajaran kecakapan hidup bagi siswa. Adapun hal-hal yang menghambat dari pelaksanaan kurikulum bahasa Arab di Sekolah Piraya Nawin Klonghin Wittaya di antaranya: siswa kurang minat dalam menghafal mufradat bahasa Arab, siswa kurang membiasakan berbicara bahasa Arab, siswa kurang disiplin untuk berangkat sekolah, dan wali siswa kurang memberikan perhatian yang seharusnya kepada siswa.[]

\section{Daftar Rujukan}

Abu Zaid, Nashr Hamid. 2015. Mafhūm al-Nashsh: Dirāsat fi Ulūm al-Qurān. Kairo: al-Hai’ ah alMishriyyah al-“ Âmmah li al-Kitâb.

Dokumentasi. 2019. Kurikulum Sekolah Piraya Nawin Klonghin Wittaya, Tahun 2019

al-Fathoni, Ahmad Fathy. 2015. Ulama Besar dari Fathoni. Kuala Lumpur. University Kebangsaan Malaysia Press.

Faududdin. 2016. Pengembangan dan Inovasi Kurikulum. Jakarta: Departemen Pendidikan dan Kebudayaan.

Fauziah, Sifa. 2015. "Sejarah Perkembangan Pendidikan Islam di ThailandSelatan (Patani) Pada Abad ke XVII-XX M", Thesis, UIN Syarif Hidayatullah

Ghony, M. Djunaidi., \& Fauzan Almanshur. 2019. Metodologi Penelitian Kualitatif. Yogyakarta: Ar-Ruzz Media

Hasan, Basyri., \& Ahmad Saebani Beni. 2017. Ilmu Pendidikan Islam. Bandung. CV Pustaka Setia.

Humaidi. 2018. "Epistemologi Kurikulum Pendidikan Sains”, Jurnal Pendidikan Islam, Vol. 2, No. 2.

Malik, M. Zamberi A. 2019. Patani dalam Tamadun Melayu. Kuala Lumpur: Dewan Bahasa dan Pustaka

Nik Mahmud, Nik Anuar. 2016. Sejarah Perjuangan Melayu Patani 1785-1954. Selangor: UKM Bangi.

Piraya Nawin Klonghin Wittaya School. 2018. Piraya Guide Book,. Pattani. Departement Academic.

Subandijah. 2019. Pengembangan dan Inovasi Kurikulum, cet. 1. Jakarta. PT. Raja Grafindo. 
Arabi : Journal of Arabic Studies

Sulung, Saifundin. 2016. "Kurikulum Pendidikan Agama Islam”, Thesis, IAIN Tulungagung.

Suparno, Paul. 2017. Filsafat Konstruktivisme dalam Pendidikan. Yogyakarta. Kanisius

Terjemah dari UU Pendidikan Nasional 2542. 2019. พระราชบัญญัติการศึกษาแห่ งชาติพ.ศ. ตะ๕๕ตแแ้ไขเพิ่มเติม

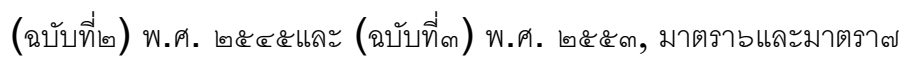

Teun A. van Dijk. 2017. 'Ilm al-Nashsh: Madkhal al-Mutadâkhil al-Ikhtishâshât, terj. dari Text Wissens Caft, Eine Interdiziplinare Einfuhrung oleh Said Hasan Buhairi. Kairo: Dār alQāhirah.

Undang-Undang Dasar Kerajaan Thai. 2019. Raj Tham Manun Heing Raj Anajak Thai 2540. Bangkok: j. Film Proses Company Limited. 